\title{
ANTIBACTERIAL ACTIVITY OF SELF-ETCH ADHESIVES
}

\author{
G. Midhun Mohan'1, Sulphi Abdul Basheer²
}

${ }^{1}$ Assistant Professor, Department of Dentistry/Oral \& Maxillofacial Surgery, Sree Gokulam Medical College and Research Foundation. ${ }^{2}$ Associate Professor, Department of Dentistry/Oral \& Maxillofacial Surgery, Sree Gokulam Medical College and Research Foundation.

\section{ABSTRACT}

\section{BACKGROUND}

Adhesion between tooth structure and the restoration is one of the most important factors determining the success of the restoration. The main reason for the failure and replacement of restorations is secondary caries. Dentin bonding agents with antibacterial effects may inhibit secondary caries formation and pulp inflammation by eliminating residual bacteria in and on dentin. Remineralisation by release of fluoride is representative, but the antibacterial effect is another important property because inactivation of bacteria means a direct strategy to eradicate the cause of dental caries.

Aim- To evaluate and compare the antibacterial effect of two different Self-Etch Adhesives- FL-Bond II (fluoride releasing bonding agent), Single Bond Universal and 0.2\% Chlorhexidine (Control) against Streptococcus salivarius and Streptococcus Mutans strains using agar well diffusion method.

\section{MATERIALS AND METHODS}

Two commercially available dentinal bonding agents to be selected, $0,2 \%$ Chlorhexidine solution to be included as a positive control. The bacteria to be used in the experiments: Streptococcus mutans and Streptococcus salivarius isolated from Mutans Agar and Mitis Salivarius Agar and both strains to be grown overnight in brain heart infusion (BHI) broth. Strains were subcultured in Tryptone Soya Agar (Enriched Media). Samples were transferred to fresh BHI medium and incubated at $37^{\circ} \mathrm{C}$ for 6 to 8 hours to achieve an appropriate bacterial density. The susceptibility tests to be performed on blood agar and for the mutans streptococci, tests also to be conducted on mitis salivarius bacitracin (MSB) agar. For the agar well diffusion test, wells were cut on agar plates and were impregnated with $10 \mu \mathrm{L}$ of each adhesive system and then immediately used. Plates were incubated at $37^{\circ} \mathrm{C}$ and examined at $24 \mathrm{hrs}$. The size of the inhibition zone ( $\mathrm{mm}$ ) was measured with sliding callipers.

\section{RESULTS}

The test results of the two different self-etch adhesives used were significantly different.

\section{CONCLUSION}

Both the tested adhesives showed promising antibacterial activity. In relation to S. mutans, FL Bond II showed similar antibacterial activity to Chlorhexidine. Although in relation to both strains (S. mutans and S. salivarius), SBU exhibited antibacterial activity; future studies comparing adhesives with and without MDP monomer have to be carried out to confirm its antibacterial activity.

\section{KEYWORDS}

Antibacterial Activity, Self-etch Adhesive, Streptococcus Mutans, Streptococcus Salivarius.

HOW TO CITE THIS ARTICLE: Mohan GM, Basheer SA. Antibacterial activity of Self-etch adhesives. J. Evolution Med. Dent. Sci. 2017;6(87):6061-6065, DOI: 10.14260/jemds/2017/1316

\section{BACKGROUND \\ In spite of considerable improvement in recent years, polymerisation shrinkage and the resultant contraction gaps at tooth-restoration interfaces continue to be a significant problem associated with composite resin restorations. ${ }^{1}$ Poor adaptation to the surrounding tooth substance may predispose to discolouration and bacterial colonisation. Secondary caries and/or pulpal inflammation may ensue. To minimise the contraction gap formation and the potential bacterial leakage, enamel and dentinal bonding resins have been developed, but so far no bonding system has been proven effective $2,3,4,5$}

'Financial or Other Competing Interest': None.

Submission 21-09-2017, Peer Review 19-10-2017,

Acceptance 25-10-2017, Published 30-10-2017.

Corresponding Author:

Dr. Sulphi Abdul Basheer,

Associate Professor,

Sree Gokulam Medial College and Research Foundation,

Venjaramoodu, Trivandrum, Kerala.

E-mail: sulphi@gmail.com

DOI: $10.14260 /$ jemds/2017/1316 to prevent pulpal involvement and hypersensitivity reactions. The placement of protective liners or base materials must still be regarded as a necessary precaution. ${ }^{6,7}$ Secondary caries may be prevented by coupling a slowly releasing compound, active against cariogenic organisms, with the resin material.8,9 Mutans streptococci, in particular Streptococcus mutans and Streptococcus sobrinus, are associated with the irritation of human dental caries, and lactobacilli are associated with the progression of the established lesion. ${ }^{10,11} \mathrm{~A}$ reduction in the amount of these bacteria in the tooth-restoration interface would be expected to influence the caries incidence. The possibility that composite or bonding resins may have an antibacterial effect is therefore attractive. Chlorhexidine has so far been the most potent antimicrobial agent to combat mutans Streptococci, 12 but is not incorporated in any of the currently marketed dental restorative resin materials. On the other hand, recent studies have demonstrated antimicrobial properties $^{8}$ as well as reduced demineralisation rates around a fluoride-releasing composite resin. ${ }^{9}$ Glass-ionomer cement used as a lining material under restorations has shown antibacterial activity in vitro towards mutans streptococci and lactobacilli. 
The Gluma dentinal bonding system appears to inhibit bacterial presence in cavity-restoration interfaces in vivo. ${ }^{13}$ The purpose of the present in vitro study was to compare the antibacterial effect/activity of two different self-etch adhesives, FL Bond II and Single Bond Universal on bacterial growth.

Current adhesive systems interact using two different strategies:

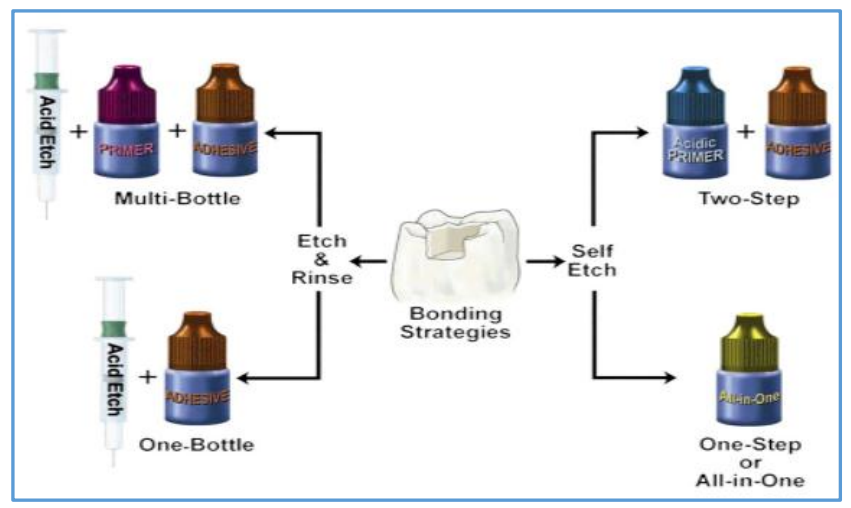

- (Franklin R. Tay; Ricardo M. Carvalho; David H. Pashley; 2004)

Major Shortcomings of current Self-etch Adhesives:

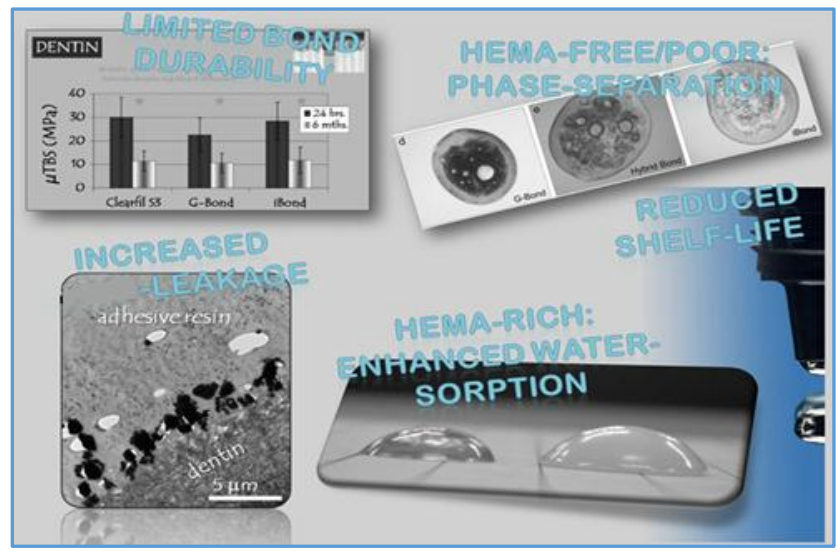

Attempts of functionalising adhesive system with antibacterial activity have been made to ensure the biological sealing of the restoration even when microleakage occurs. ${ }^{14}$ For dentin bonding systems, their antibacterial effects are discussed in terms of inactivation of bacteria which invade the adhesive interface by microleakage. ${ }^{15}$

\section{Aim}

To evaluate and compare the in vitro inhibitory effect of 2 different self-etch adhesives on bacterial growth.

\section{MATERIALS AND METHODS}

This is a prospective case-control study carried out in the Department of Dentistry, Sree Gokulam Medical College and Research Foundation. The duration of the study was 45 days. The materials used in this study included two different selfetch adhesives: FL-Bond II (fluoride releasing bonding agent), Single Bond Universal (Single-bottle solution for all surfaces, used reliably in total-etch, self-etch or selective-etch mode for both direct and indirect restorations).
$0.2 \%$ Chlorhexidine solution (ICI Dental) was included as a positive control.

The specifications of the two self-etch adhesives are listed in Table 1.

\begin{tabular}{|c|c|c|c|}
\hline Adhesive & Manufacturer & Batch number & Type \\
\hline FL Bond II & SHOFU & Pn1308 & $\begin{array}{c}2 \text { bottles } \\
2 \text { steps }\end{array}$ \\
\hline $\begin{array}{c}\text { Single bond } \\
\text { universal }\end{array}$ & $3 \mathrm{~m}$ & 41453 & $\begin{array}{c}1 \text { bottle } \\
1 \text { step }\end{array}$ \\
\hline \multicolumn{3}{|c|}{ Table 1. Adhesive Systems Tested } \\
\hline
\end{tabular}

Both the adhesives used as well as the positive control were impregnated on Paper disks to be placed onto the Agar petri dishes.

\section{Saliva Collection}

Unstimulated saliva was collected from 30 volunteers with high plaque index. The Collected saliva was stored in sterile containers and was diluted with saline (1:4 ratio).

\section{Bacterial Strains and Growing Conditions}

Selective media used for bacterial isolation were MutansSanguis Agar and Mitis Salivarius Agar. The strains, Streptococcus Mutans and Streptococcus Salivarius, isolated from the selective media were obtained from Culture Collection Centre, Microbiology Department of Sree Gokulam Medical College, KUHS, Trivandrum. Strains were subcultured in Tryptone Soya Agar (enriched media) to enhance bacterial growth. Both isolated strains were cultured in Brain Heart Infusion Agar (1.8\% w/v) (BHI, Difco, CA, USA) supplemented with $10 \%(\mathrm{v} / \mathrm{v}$ ) Horse serum (Oxoid, Rodano Milan, Italy). These source cultures for the experiments were statically incubated at $37^{\circ} \mathrm{C}$ under aerobic conditions and reduced to a final density as determined by comparing the sample with a standard curve relating to cell number.

\section{Preparation of Specimens}

There are three groups ( 2 test groups and 1 control group), each of which comprises 10 samples as shown in the table below. For the agar plate well diffusion test, two $90 \mathrm{~mm}$ Petri plates were prepared. Wells were cut on these Agar plates. Both the adhesives (FL Bond II and Single Bond Universal) were cured using a LED curing light in soft startpolymerisation mode (Celalux 2 High-Power LED curing-light; Voco GmbH, Cuxhaven, Germany) for 20 seconds at a light intensity of $1000 \mathrm{~mW} / \mathrm{cm}^{2}$. All materials were prepared according to manufacturer's recommendations. The positive control used was $0.2 \%$ solution of Chlorhexidine digluconate (CHX).

\section{Agar Well Diffusion Test}

Approximately, $3 \mathrm{~mL}$ of an overnight suspension of each bacterial strain $(1 \times 108$ colony forming unit $/ \mathrm{mL}, \mathrm{CFU} / \mathrm{mL})$ grown in BHI with $10 \%$ horse serum was used as inoculum onto the agar plates. The incubation was performed for 20 minutes at $37^{\circ} \mathrm{C}$ and finally the excess of bacterial cells was removed. Each paper disk impregnated with the adhesive system and positive control, as previously indicated was then aseptically placed onto the wells on each of the agar plate one at a time. 
The plates were incubated at $37^{\circ} \mathrm{C}$ and examined at $24 \mathrm{hrs}$. The antibacterial activity of each adhesive system was measured from clear circular areas (halos) around them. The size of the inhibition zone was measured with sliding callipers and calculated as follows:

Size of inhibition zone $=$ diameter halo - diameter specimen $/ 2$.

The results were recorded in terms of the average diameter of inhibition zone.

\section{Statistical Analysis}

Kolmogorov-Smirnov tests result shows that the data follows normal distribution. Therefore, to analyse the data, one way ANOVA is used followed by Tukey's HSD post hoc test for multiple comparison. SPSS 22.0.0.0 version was used for statistical analysis.

Descriptive statistics, including mean, standard deviation, minimum, median and maximum were calculated for each group tested. Data were assessed to be normal by means of the Kolmogorov and Smirnov test.

An Analysis Of Variance (ANOVA) was carried out to compare mean values within each group and Tukey HSD test was performed to compare pair wise, multiple pair wise comparisons, as post hoc. Significance was set at $\mathrm{p}<0.05$.

\section{RESULTS}

Table 1 compares the two dentin bonding systems- FL Bond II, Single Bond Universal and the Control Group Chlorhexidine Digluconate in the production of inhibition zones against Streptococcus Mutans and Streptococcus Salivarius

Descriptive statistical analyses are reported in Table II. One Way ANOVA test showed the presence of significant differences between the groups.

Tukey HSD test showed that when testing antibacterial activity with S. salivarius the highest growth inhibition values $(\mathrm{p}<0.001)$ were reported with Chlorhexidine solution (positive control). FL Bond II showed significantly lower values than Chlorhexidine, but significantly higher values than Single Bond Universal $(\mathrm{p}<0.001)$.

\begin{tabular}{|l|c|c|c|c|c|}
\hline & Group & $\mathbf{N}$ & Mean & $\begin{array}{c}\text { Std. } \\
\text { Deviation }\end{array}$ & P-Value \\
\hline \multirow{4}{*}{ S. Mutans } & FL & 10 & 27.10 & 1.663 & \\
\cline { 2 - 6 } & SBU & 10 & 23.70 & 2.111 & \multirow{2}{*}{$<0.001$} \\
\cline { 2 - 5 } & Control & 10 & 28.20 & 1.932 & \\
\cline { 2 - 5 } & Total & 30 & 26.33 & 2.682 & \\
\hline \multirow{5}{*}{ S. Salivarius } & FL & 10 & 27.20 & 1.317 & \multirow{4}{*}{$<0.001$} \\
\cline { 2 - 6 } & SBU & 10 & 24.50 & 1.434 & \\
\cline { 2 - 6 } & Control & 10 & 30.80 & 1.229 & \\
\cline { 2 - 5 } & Total & $\mathbf{3 0}$ & $\mathbf{2 7 . 5 0}$ & $\mathbf{2 . 9 2 1}$ & \\
\hline
\end{tabular}

\begin{tabular}{|c|c|c|c|}
\hline Dependent Variable & \multicolumn{2}{|c|}{ Pair } & P-Value \\
\hline \multirow{3}{*}{ S. Mutans } & \multirow{2}{*}{ FL } & SBU & 0.001 \\
\cline { 2 - 4 } & & Control & 0.414 \\
\cline { 2 - 4 } & SBU & Control & $<0.001$ \\
\hline \multirow{3}{*}{ S. Salivarius } & \multirow{2}{*}{ FL } & SBU & $<0.001$ \\
\cline { 2 - 4 } & & Control & $<0.001$ \\
\cline { 2 - 4 } & SBU & Control & $<0.001$ \\
\hline
\end{tabular}

When testing antibacterial activity with S. mutans, highest growth inhibition values $(\mathrm{p}<0.001)$ were reported with Chlorhexidine solution (Control). FL Bond II showed lower value than Chlorhexidine, but either values showed no significant difference $(p>0.414)$ but FL Bond showed significantly higher value than Single Bond Universal $(p<0.05)$.

When testing antibacterial activity with Streptococcus salivarius, the highest growth inhibition values were reported with Chlorhexidine solution (Control) $(\mathrm{p}<0.001)$. Significantly lower values were reported with FL Bond II $(\mathrm{p}<0.001)$, which showed significantly higher values than Single Bond Universal $(\mathrm{p}<0.001)$.


Graphs I and II compare the mean values of antibacterial activity of the two Self-etch Adhesives and Chlorhexidine digluconate (Control) against both strains Streptococcus Mutans and Streptococcus Salivarius.

\section{DISCUSSION}

Secondary caries is still the main cause for replacement of restorations. During removal of carious tissue, bacteria can remain entrapped in the dentinal substrate.16,17 Many attempts have been made to produce dental materials that inhibit bacterial growth and no currently available adhesive system completely eliminates microleakage at the tooth/restoration interface. , $^{4,18}$

The current study used the agar diffusion test to evaluate the efficacy of two different self-etch adhesives in inhibiting the bacterial growth of two microorganisms.

The bacterial species used in this study are related to caries disease: S. salivarius is commonly found colonising the 
healthy oral cavity and is related to the initial colonisation of dental surfaces or to smaller caries lesions; while Streptococcus mutans is related to the progression of caries lesions. 19-22 The agar diffusion test has been widely used to evaluate the antibacterial activity of dental materials. The zones of growth inhibition provided by the materials depend on the toxicity of the material against the bacteria tested, and on the diffusibility of the material across the culture medium used. ${ }^{23}$ So, although the agar diffusion test is easier to perform, the inhibitory properties of solid materials placed on agar surfaces are dependent upon the hydrophilicity of the material, its diffusion coefficient in agar gel, and the ability of material to wet the agar surface. ${ }^{24} \mathrm{~A}$ material that diffuses more easily, in addition to its direct cytotoxicity, will provide larger zones of inhibition. The self-etch adhesives that were tested presented different antibacterial effects, however, they resulted in different mean values of inhibition zones. The adhesive system that presented the highest growth inhibition values was FL Bond II. In relation to S. mutans, FL Bond II showed similar antibacterial activity to Chlorhexidine. The primer of Single Bond Universal incorporates a MDPB monomer, which is synthesised by combining a methacryloyl group with a quaternary ammonium that present antibacterial growth promoters and plaque accumulation inhibitors, and therefore have the potential to kill or inhibit bacteria which are inadvertently left in a prepared cavity.

\section{CHX}

Chlorhexidine being a positively charged hydrophobic and lipophilic molecule interacts with phospholipids and lipopolysaccharides on the cell membrane of bacteria and then enters the cell through some type of active or passive transport mechanism. Its efficacy is because of the interaction of the positive charge of the molecule and the negatively charged phosphate groups on microbial cell walls, thereby altering the cell's osmotic equilibrium. This increases the permeability of the cell wall, which allows the CHX molecule to penetrate into the bacteria. 25

\section{FL Bond II}

In order to provoke antimicrobial effect, fluoride enters the bacterial cell. Fluoride diffuses into cariogenic bacteria in the form of HF. At the lower external $\mathrm{pH}$, more $\mathrm{HF}$ is formed and more of it diffuses into the cell. Once inside the cell, the HF dissociates into $\mathrm{H}+$ and $\mathrm{F}-$, because of a higher internal $\mathrm{pH}$ of cells, such as oral streptococci, than external. ${ }^{26}$

This continued diffusion and dissociation leads to the accumulation of fluoride in the cell and the acidification (accumulation of $\mathrm{H}+$ ) of the cytoplasm. Fluoride ions within the cell interfere with the glycolytic enzyme (enolase) activity and adenosine triphosphatase.

Thus, fluoride inhibits effectively the carbohydrate metabolism of acidogenic oral bacteria. It is reported that the S-PRG filler forms an acid resistant layer in and beneath the complex of resin-reinforced dentin (hybrid layer) due to the continuous release of cariostatic fluoride that stimulates the remineralisation of areas prone to secondary caries. ${ }^{14}$

\section{Single Bond Universal}

Primer incorporates a MDPB, which is synthesised by combining a methacryloyl group with a quaternary ammonium that present antibacterial growth promoters and plaque accumulation inhibitors and therefore have the potential to kill or inhibit bacteria. ${ }^{27}$

MDPB monomer has a strong antibacterial activity and after curing, MDPB monomer is covalently bonded to the polymer network and acts as a contact inhibitor against the bacteria that comes in direct contact with the polymer. ${ }^{27}$

A self-etch primer containing 5\% MDPB killed S. mutans within 30 seconds of contact before curing. ${ }^{24}$

Following copolymerisation with other monomers, this self-etch primer had an inhibitory effect on the growth and adherence of bacteria on its surface. ${ }^{24}$

The properties of materials used in this experiment may have influenced the results, but these factors are less important when using bacterial suspensions because the materials are in direct contact with aqueous media. Further studies with another method such as microdilution broth technique are necessary to evaluate the bactericidal activity of these adhesive systems.

\section{CONCLUSION}

Within the limitations of this study, it can be concluded that: Both the tested adhesives showed promising antibacterial activity.

In relation to S. mutans, FL Bond II showed similar antibacterial activity to Chlorhexidine.

Although in relation to both strains (S. mutans and S. salivarius), SBU exhibited antibacterial activity; future studies comparing adhesives with and without MDP monomer have to be carried out to confirm its antibacterial activity.

\section{REFERENCES}

[1] Roulet JF, Noack MJ. Criteria for substituting amalgam with composite resins. Int Dent J 1991;41(4):195-205.

[2] Cheung GSP. An in vitro evaluation of five dentinal adhesives in posterior restorations. Quintessence Int I990;21(6):513-6.

[3] Lundin SA, Norén JG, Warfvinge J. Marginal bacterial leakage and pulp reactions in class ii composite resin restorations in vivo. Swed Dent J 1990;14(4):185-92.

[4] Prati C, Nucci C, Davidson CL, et al. Early marginal leakage and shear bond strength of adhesive restorative systems. Dent Mater 1990;6(3):195-200.

[5] Tjan AHL, Tan DE. Microleakage at gingival margins of class $\mathrm{V}$ composite resin restorations rebonded with various low-viscosity resin systems. Quintessence Int 1990;22(7):565-73.

[6] Bergenholtz G. Iatrogenic injury to the pulp in dental procedures: aspects of pathogenesis, management and preventive measures. Int Dent J 1991;41(2):99-110.

[7] Brannstrom M, Mattsson B, Torstenson B. Materials techniques for lining composite resin restorations: a critical approach. J Dent J 1991;19(2):7l-9.

[8] Scherer W, Lippman N, Kaim J. Antimicrobial properties of glass-ionomer cements and other restorative materials. Oper Dent 1989;14(2):77-81. 
[9] Arends J, Ruben J, Dijkman AG. Effect of fluoride release from a fluoride-containing composite resin on secondary caries: an in vitro study. Quintessence Int 1990;21(8):671-74.

[10] Emilson CG, Krasse B. Support for and implications of the specific plaque hypothesis. Scand J Dent Res I985;93(2):96-104.

[11] Loesche WJ. Role of streptococcus mutans in human dental decay. Microbiol Rev 1986;50(4):353-80.

[12] Krasse B, Emilson CG. Reduction of streptococcus mutans in humans. In: Hamada S, ed. Molecular microbiology and immunology of streptococcus mutans. Amsterdam: Elsevier 1986:381-91.

[13] Tay FR, Carvalho RM, Pashley DH, et al. Water movement across bonded dentin-too much of a good thing. J Appl Oral Sci 2004;12:12-25.

[14] Li F, Chen J, Chai Z, et al. Effects of a dental adhesive incorporating antibacterial monomer on the growth, adherence and membrane integrity of streptococcus mutans. J Dent 2009;37(4):289-96.

[15] Cristiane D, Thias de Cassia N, Denise Madalena Palomari S, et al. Effect of light activation on the antibacterial activity of dentin bonding agents. Brazilian Journal of Oral Sciences 2010;8(4):175-80.

[16] van Houte J. Role of micro-organisms in caries etiology. J Dent Res 1994;73(3):672-81.

[17] Deligeorgi V, Mjör IA, Wilson NH. An overview of reasons for the placement and replacement of restorations. Prim Dent Care 2001;8(1):5-11.

[18] Koliniotou-Koumpia E, Dionysopoulos P, Koumpia E. In vivo evaluation of microleakage from composites with new dentine adhesives. J Oral Rehabil 2004;31(10):1014-22.
[19] Fraga RC, Siqueira JF, de Uzeda M. In vitro evaluation of antibacterial effects of photo-cured glass ionomer liners and dentin bonding agents during setting. J Prosthet Dent 1996;76(5):483-6.

[20] Montanaro L, Campoccia D, Rizzi S, et al. Evaluation of bacterial adhesion of streptococcus mutans on dental restorative materials. Biomaterials 2004;25(18):445763.

[21] Poggio C, Dagna A, Chiesa M, et al. SEM evaluation of the root canal walls after treatment with Tetraclean. Int J Artif Organs 2010;33(9):660-6.

[22] Poggio C, Arciola CR, Dagna A, et al. Photoactivated disinfection (PAD) in endodontics: an in vitro microbiological evaluation. Int $\mathrm{J}$ Artif Organs 2011;34(9):889-97.

[23] Giammanco GM, Cumbo EM, Luciani A, et al. In vitro evaluation of the antibacterial activity of cured dentin/enamel adhesive incorporating the antimicrobial agent MDPB. New Microbiol 2009;32(4):385-90.

[24] Prati C, Fava F, Di Gioia D, et al. Antibacterial effectiveness of dentin bonding systems. Dent Mater 1993;9(6):338-43.

[25] Gomes BP, Souza SF, Ferraz CC. Effectiveness of 2\% Chx gel and $\mathrm{CAOH}$ against $\mathrm{E}$ faecalis in bovine root dentine in vitro. IEJ 2003;36(4):267-75.

[26] Meiers. Fluoride and dental caries: second thoughts in view of recent evidence. Editorial Fluoride 2011;44(1):1-6.

[27] Kuramoto A, Imazato S, Walls AW, et al. Inhibition of root caries progression by an antibacterial adhesive. J Dent Res 2005;84(1):84-93. 